\title{
QUANTITATIVE ANALYSISOF STEVIOSIDE AND REBAUDIOSIDE A IN STEVIAREBAUDIANA LEAVES USING INFRARED SPECTROSCOPY AND MULTIVARIATE CALIBRATION
}

\author{
YOHANNES MARTONO ${ }^{1}$, ABDUL ROHMAN ${ }^{2 *}$ \\ ${ }^{1}$ Chemistry Department, Satya Wacana Christian University, Salatiga 50733, Central Java, Indonesia, ${ }^{2}$ Faculty of Pharmacy, Gadjah Mada \\ University, Yogyakarta 55221, Indonesia \\ Email: abdulrohmanugm@gmail.com \\ Received: 20 Jun 2018, Revised and Accepted: 19 Nov 2018
}

ABSTRACT

Objective: The objective of this research was to develop Fourier transform infrared (FTIR) spectroscopy in combination with multivariate analysis of partial least square (PLS) regression for quantitative analysis of stevioside and rebaudioside A in S. rebaudiana leaves extract.

Methods: Stevia rebaudiana leaves with various ages were obtained from several high hills in Central Java, Indonesia. The extract samples were scanned using FTIR spectrophotometer in wavenumbers region of 4000-650 $\mathrm{cm}^{-1}$. PLS calibration model was established by plotting the actual value of stevioside and rebaudioside $\mathrm{A}$ as determined by high-performance liquid chromatography (HPLC) and FTIR predicted value. The performance of PLS regression was evaluated using coefficient determination $\left(R^{2}\right)$, root mean square error of calibration (RMSEC), root mean square error of prediction (RMSEP).

Results: PLS regression for stevioside determination was successfully established using the combined wavenumber region of $671-1450$ and 3279 $3301 \mathrm{~cm}^{-1}$. PLS regression revealed $\mathrm{R}^{2}$ of 0.9952 with RMSEC value of $0.84 \%$. Meanwhile, rebaudioside A was determined at wavenumber region of 921-1508 $\mathrm{cm}^{-1}$ using normal spectra. PLS model revealed $\mathrm{R}^{2}$ and RMSEC of 0.9911 and $0.70 \%$, respectively.

Conclusion: FTIR spectroscopy in combination with multivariate analysis of PLS regression could be used as an alternative method for quantitative analysis ofstevioside and rebaudioside A in S. rebaudiana leaves.

Keywords: FTIR spectroscopy, Partial least square regression, Stevia rebaudiana, Stevioside, Rebaudioside A

(C) 2019 The Authors. Published by Innovare Academic Sciences Pvt Ltd. This is an open access article under the CC BY license (http://creativecommons.org/licenses/by/4.0/) DOI: http://dx.doi.org/10.22159/ijap.2019v11i1.28029

\section{INTRODUCTION}

Stevioside (STE) and rebaudioside A (RBA) are major diterpene glycosides in Stevia rebaudiana plant. These compounds have high sweetness but no caloric value $[1,2]$. STE and RBA in $S$. rebaudiana also have some biological bioactivities such as antidiabetic $[3,4]$, antioxidant $[5,6]$, antihypertensive [7], antidiarrheal [8], and anticancer [9]. Due to their beneficial effects, stevioside and rebaudioside A were increasingly used in industry [10]. USA permitted the use of rebaudioside A only as Generally Recognazie As Safe (GRAS) in purified extract form. WHO determine Admisible Daily Intake (ADI) of STE of $0-4 \mathrm{mg} / \mathrm{kg}$ body weight $[11,12]$.

Due to regulations and high valuable economics of STE and RBA, quantitative analysis method of respected compounds was needed to be developed and established. Most methods used for STE and RBA determination were based on high performance liquid chromatography (HPLC). Both normal phase and reversed phase HPLC and high performance thin layer chromatography (HPTLC) methods have been developed and validated for quantitative analysis of STE and RBA [13-17]. The lack of chromatographic separation will influence the method validation assay. Therefore, simple methods based on spectroscopy were developed to determine STE and RBA.

Vibrational spectroscopy in combination with chemometrics have been used to determine STE and RBA [18] due to its property as fingerprint [19]. The simultaneous determination of respected compounds in some extracts or natural products can be achieved by FTIR spectroscopy combined with PLS calibration [20, 21]. FTIR spectroscopy offered qualitative and quantitative analyses of targeted samples including pharmaceutical products [22-24]. This present study was aimed to evaluate the application of FTIR spectroscopy combined with multivariate calibration for the quantitative analysis of STE and RBA in ethanolic extracts of $S$. rebaudiana.

\section{MATERIALS AND METHODS}

\section{Materials}

Reference Standards of stevioside and rebaudioside A were obtained from WAKO, Japan with purity $>99.0 \%$. Acetonitrile (HPLC grade), methanol (HPLC grade), trifluoroacetic acid (TFA, pro-analysis grade) and ethanol (pro-analysis grade) were purchased from Merck (Darmstadt, Germany). Millipore filter $(0.45 \mu \mathrm{m})$ with diameter 2.5 $\mathrm{cm}$ was obtained from Whatman (United Kingdom).

\section{Plants materials and extraction}

Stevia rebaudiana leaves with various ages were obtained from several high hills in Central Java, Indonesia. Extraction was done according to Martono et al. [25]. Leaves samples were dried using cabinet dryer at $50{ }^{\circ} \mathrm{C}$ at night. Dried leaves were powdered. A- $0.5 \mathrm{~g}$ of powdered dried leaves was extracted using $25 \mathrm{ml}$ ethanol $60 \%$ using ultrasonic at $40{ }^{\circ} \mathrm{C}$ for $15 \mathrm{~min}$. The filtrate was collected and the residue was re-extracted in the same way. Extraction was repeated 3 times. The filtrate collected was adjusted until $100 \mathrm{ml}$ with ethanol $60 \%$. Subsequently, the filtrate was evaporated under vacuum and the solvent residue was dried over water bath with water steam. Extract was dried in oven at $105{ }^{\circ} \mathrm{C}$ for 30 minute. Dried extract was pulverized and kept in freezer until being used for further analysis.

\section{Measurement of FTIR spectra}

Dried extract was placed on Horizontal Attenuated Total Reflectance (HATR) equipment at room temperature $\left(25^{\circ} \mathrm{C}\right)$. FTIR spectra of all samples were scanned using a FTIR spectrophotometer ABB MB3000 (Clairet Scientific, Northampton, UK), equipped with deuterated triglycine sulphate (DTGS) detector and beam splitter of germanium. FTIR spectra were scanned in wavenumber region of $4000-650 \mathrm{~cm}^{-1}$ with resolution of $4 \mathrm{~cm}^{-1}$ and number of scanning of 32. All spectra were calibrated using background of air spectrum as reference. After every scan, a new reference air background spectrum was taken. These spectra were recorded as absorbance values at each data point in triplicate.

\section{Determination of STE and RBA using HPLC}

PLS calibration model was established by plotting the actual value of STE and RBA as determined by HPLC and FTIR predicted value. The determination of actual value of STE and RBA was performed using 
HPLC as reference method according to Martono et al. [25]. Analytes were separated using Eurosphere RP-18 $(250 \times 4.6 \mathrm{~mm}, 5 \mu \mathrm{m})$ column equipped with guard column with same stationary phase. Column was kept at $30^{\circ} \mathrm{C}$ in thermostat. A mixture of water: methanol $(90: 10 \mathrm{v} / \mathrm{v}$, adjusted to $\mathrm{pH}$ of 3.0 by phosphoric acid), acetonitrile and TFA was used as mobile phase with the ratio of $65: 35: 0.1(\mathrm{v} / \mathrm{v} / \mathrm{v})$. The mobile phase was delivered isocratic ally at $0.6 \mathrm{ml} / \mathrm{min}$. UV detector was set at $210 \mathrm{~nm}$. The injection volume was $20 \mu \mathrm{l}$. Running time analysis was 15 minute. Concentration of STE and RBA were determined by plotting peak area using external calibration method.

\section{Statistical analysis}

Multivariate calibration of PLS was established using Horizon MB FTIR software version 3.0.13.1 (ABB, Canada) included in FTIR spectrophotometer. PLS correlated the actual values of STE and RBA obtained from HPLC determination and predicted value established from FTIR spectra. Validation was performed using the leave one out technique. The performance of PLS regression was evaluated using coefficient determination $\left(R^{2}\right)$, root mean square error of calibration (RMSEC), root mean square error of prediction (RMSEP) [21].

\section{RESULTS AND DISCUSSION}

\section{Determination STE and RBA by RP-HPLC}

STE and RBA have similar polarity. They differ only in number of sugar moieties attached at C-19 diterpene structure. RBA has 3 sugar molecules attached at C-19 of diterpene molecule, so that RBA is more polar compared to STE. Higher polarity of RBA makes this compound has shorter retention time than STE during reversed phase HPLC separation [1]. A mixture of mobile phase used has appropriate polarity to meet complete separation of STE and RBA with resolution (Rs) value $>2.00$. The example separation profile of STE and RBA along with its chemical structures in dried powder extract was shown in fig. 1. RBA and STE have retention time at $9.283 \mathrm{~min}$ and $10.133 \mathrm{~min}$, respectively.

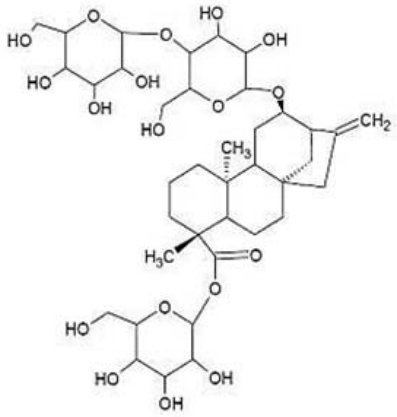

Sstevioside

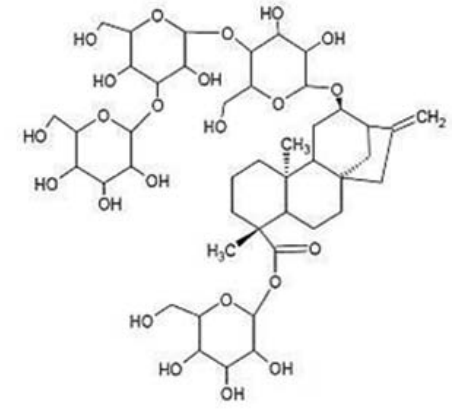

Rebaudioside A

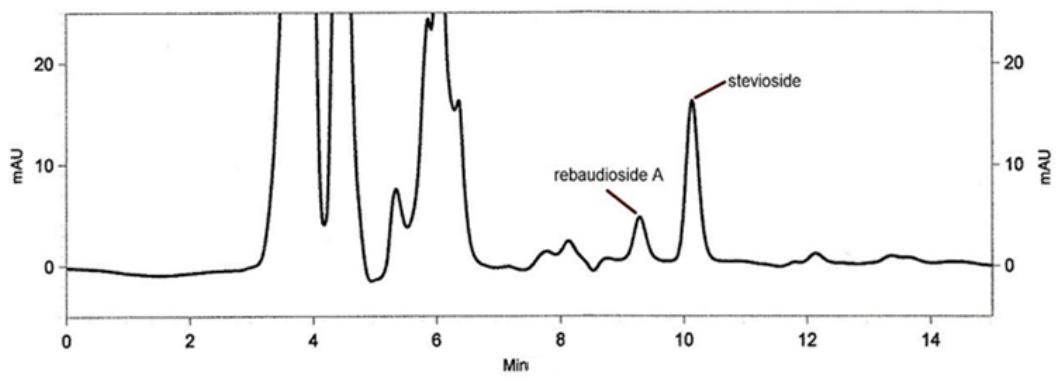

Fig. 1: Reversed phase HPLC chromatogram of stevioside and rebaudioside a along with its chemical structure in dried powder ethanol extract of Stevia rebaudiana leaves taken from polobogo, central Java, Indonesia. Time retention of rebaudioside A and stevioside were \pm 9.283 and $10.133 \mathrm{~min}$, respectively

In general, STE is the major steviol glycosides contained in S. rebaudiana leaves followed with RBA [26]. The contents of STE and RBA were influenced by some factors such as photoperiod, irradiance, intra-and inter-cultivar variations, temperature, and available nutrients [27]. The contents of STE and RBA in various ethanolic leave extracts at different region, altitude, age of leaves, time harvesting, and variety was presented in table 1 . Level of RBA varied from $2.16 \pm 0.26 \%$ to $16.94 \pm 0.07 \%$, while STE level varied from $13.51 \pm 0.34 \%$ to $45.20 \pm 6.00 \%$. The content of STE and RBA based on HPLC determination will be used as actual value during PLS regression modelling.

Table 1: Level of stevioside and rebaudioside A (\% wt/wt \pm SD) in various evaluated dried powder ethanol extract of Stevia rebaudiana leaves $(n=3)$

\begin{tabular}{|c|c|c|c|}
\hline Sample & Variation & Rebaudioside A (\% wt/wt \pm SD) & Stevioside (\%wt/wt \pm SD) \\
\hline Bandungan & age of leaves ( $4 \mathrm{w})$, altitude $(900 \mathrm{~m})$, seed from Bandungan & $16.94 \pm 0.07$ & $21.48 \pm 0.94$ \\
\hline Gedongsongo A & age of leaves ( $4 \mathrm{w})$, altitude (1400 m), seed from Bandungan & $14.98 \pm 0.21$ & $22.12 \pm 0.46$ \\
\hline Gedongsongo B & age of leaves ( $6 \mathrm{w})$, altitude $(1400 \mathrm{~m})$ seed from Tawangmangu & $2.84 \pm 0.12$ & $30.78 \pm 0.08$ \\
\hline Pakis & ages of leaves $(6 \mathrm{w})$, altitude $(1400 \mathrm{~m})$ seed from Tawangmangu & $2.76 \pm 0.53$ & $25.71 \pm 1.34$ \\
\hline Poloboga A & age of leaves ( $6 \mathrm{w})$, altitude $(800 \mathrm{~m})$, seed from Tawangmangu & $4.80 \pm 0.09$ & $20.58 \pm 0.06$ \\
\hline Poloboga B & age of leaves ( $8 \mathrm{w})$, altitude $(800 \mathrm{~m})$, seed from Tawangmangu & $7.05 \pm 0.10$ & $30.64 \pm 0.26$ \\
\hline Poloboga $\mathrm{C}$ & age of leaves ( $5 \mathrm{~d})$, altitude $(800 \mathrm{~m})$, seed from Tawangmangu & $3.31 \pm 0.59$ & $13.52 \pm 0.19$ \\
\hline Poloboga D & age of leaves ( $6 \mathrm{w})$, altitude $(800 \mathrm{~m})$, seed from Gedongsongo & $9.12 \pm 0.40$ & $13.51 \pm 0.34$ \\
\hline Poloboga E & age of leaves ( $4 \mathrm{w})$, altitude $(800 \mathrm{~m})$, seed from Tawangmangu & $2.74 \pm 0.00$ & $13.85 \pm 0.45$ \\
\hline Tajuk A & age of leaves (12 w), altitude (1200 m), seed from Balitro & $9.04 \pm 0.08$ & $40.62 \pm 1.17$ \\
\hline Tajuk B & age of leaves $(4 \mathrm{w})$, altitude $(1200 \mathrm{~m})$, seed from Balitro & $7.24 \pm 0.69$ & $33.86 \pm 1.74$ \\
\hline Tajuk C & age of leaves $(16 \mathrm{w})$, altitude $(1200 \mathrm{~m})$, seed from Kintamani & $2.16 \pm 0.26$ & $25.04 \pm 1.17$ \\
\hline Tajuk D & age of leaves $(4 \mathrm{w})$, altitude $(1200 \mathrm{~m})$, seed from Tigra & $7.96 \pm 0.66$ & $21.98 \pm 0.06$ \\
\hline Tawangmangu & age of leaves ( $8 \mathrm{w})$, altitude $(1200 \mathrm{~m})$ & $9.79 \pm 1.10$ & $45.20 \pm 6.00$ \\
\hline
\end{tabular}




\section{Analysis of STE and RBA using FTIR spectra}

FTIR spectra of several dried powder ethanol Stevia leaves extracts were presented in fig. 2 . Wide and intense absorption at $3418 \mathrm{~cm}^{-1}$ corresponded to the stretching vibration of the $\mathrm{OH}$ bond $(-\mathrm{OH}$ stretching) and was associated with the presence of hydrogen bond. Absorption at $2916 \mathrm{~cm}^{-1}$ was characteristic of stretching- $\mathrm{CH} \mathrm{sp}{ }^{3}$ bond.
Intense peaks at 1736 and $1597 \mathrm{~cm}^{-1}$ corresponded to stretching vibrational- $\mathrm{C}=0$ bond. Bending vibrational of- $\mathrm{CH}$ bond was observed at 1415 and $1385 \mathrm{~cm}^{-1}$. Furthermore, high intense peaks at 1030 and $1065 \mathrm{~cm}^{-1}$ corresponded to C-O derived from steviol glycoside and was characteristic absorption band of the glycosidic bond. Finally, peaks at $891 \mathrm{~cm}^{-1}$ and $814 \mathrm{~cm}^{-1}$ were recognized to bending vibration of $=\mathrm{CH}$ and $=\mathrm{CH}_{2}$ bonds, respectively [28].

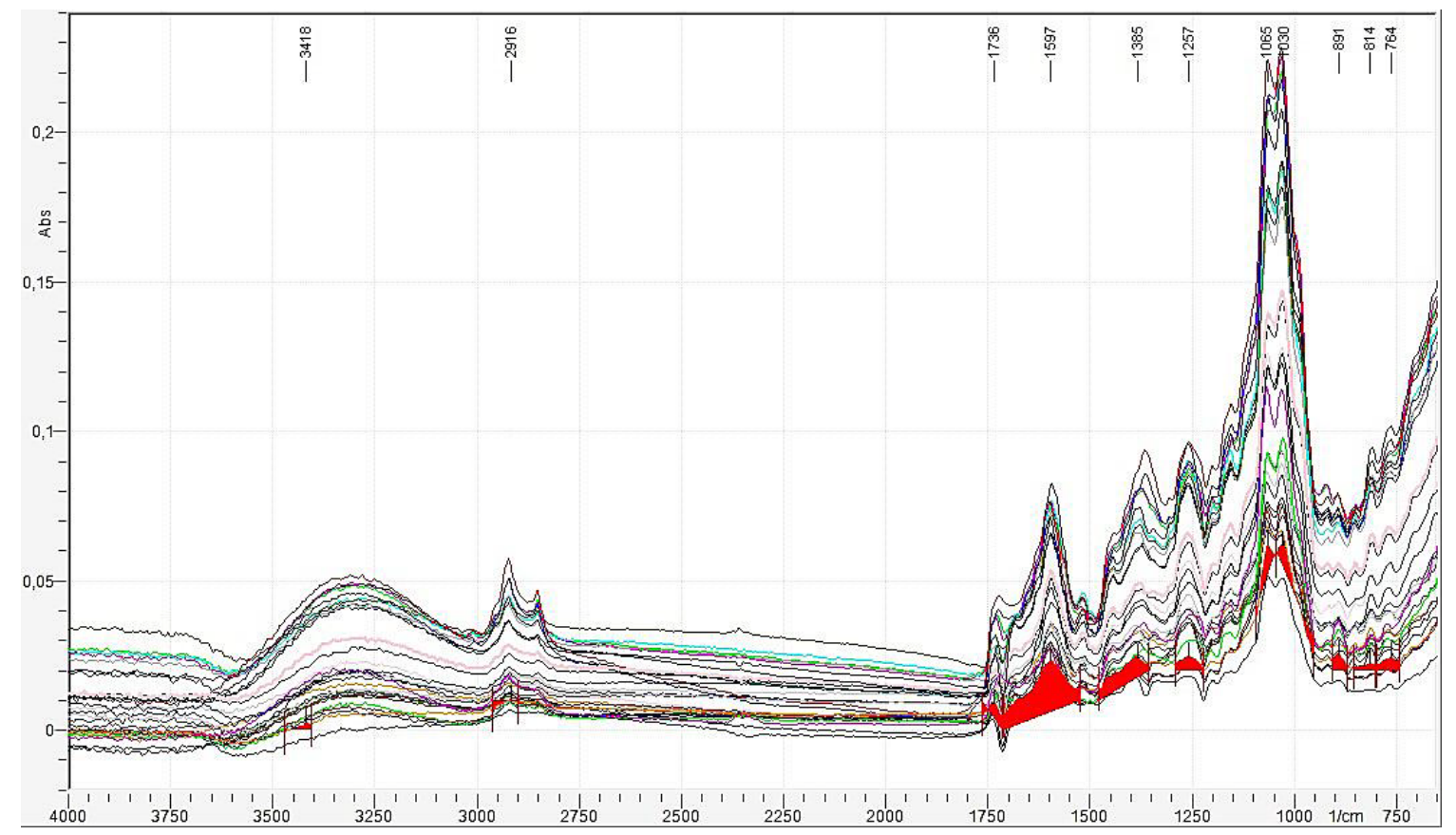

Fig. 2: The FTIR spectra of dried powder ethanolic stevia leaves extracts scanned at mid infrared region $\left(4000-650 \mathrm{~cm}^{-1}\right) . \mathrm{X}^{-a x i s}$ : Wavenumbers and Y-axis: response (absorbance)

Table 2: FTIR spectra preprocessing and PLS regression models in selected wavenumber region for stevioside determination $(n=3)$

\begin{tabular}{|c|c|c|c|c|c|}
\hline Analytes & Pre-processed spectra & Selected wave number region $\left(\mathrm{cm}^{-1}\right)$ & PLS regression model & $\mathbf{R}^{2}$ & RMSEC \\
\hline \multirow[t]{4}{*}{ Stevioside } & Original & $1068-1539$ & $y=0.8660 x+347.62$ & 0.9068 & 1.77 \\
\hline & 2nd derivatif & 848-1489 & $y=0.6626 x+732.38$ & 0.9154 & 1.96 \\
\hline & SNV & $756-1639$ & $y=0.8393 x+421.53$ & 0.9233 & 1.64 \\
\hline & MSC & $671-1450$ & $y=0.9285 x+190.13$ & 0.9836 & 1.08 \\
\hline \multirow[t]{4}{*}{ Rebaudioside A } & Original & $921-1508$ & $y=0.9775 x+16.19$ & 0.9911 & 0.70 \\
\hline & 2nd derivatif & $891-1458$ & $y=0.7292 x+155.69$ & 0.8840 & 1.34 \\
\hline & SNV & 899-1531 & $y=0.9702 x+27.26$ & 0.9799 & 0.84 \\
\hline & MSC & $841-1820$ & $y=0.91837 x+60.53$ & 0.9488 & 1.05 \\
\hline
\end{tabular}

SNV = Standard Normal Variate; MSC = Multiplicative Scatter (or Signal) Correction.

During analysis using FTIR spectra, undesired features that can be raised from noise and systematic behavior need to be eliminated. Pre-processing spectra could eliminate undesired features of FTIR spectra. Initially, spectra were pre-processed using transformation of standard normal variate (SNV), multiplicative scatter (or signal) correction (MSC), and second derivatives. Optimization of PLS model on different pre-processing spectra established the different PLS models. The pre-processing spectra selected were based on their ability to provide high coefficient determination $\left(\mathrm{R}^{2}\right)$ and minimum value of RMSEC on selected wavenumber region. Pre-processed spectra of MSC revealed better PLS regression model at wavenumber region of $671-1450 \mathrm{~cm}^{-1}$ for STE analysis, while original spectra offered better PLS regression model at selected wavenumber region (930-1520 $\left.\mathrm{cm}^{-1}\right)$ for RBA determination. Table 2 presented the optimization of pre-processing spectra during PLS modeling for STE and RBA analyses, respectively.

Validation of PLS regression model was done using leave-one-out cross validation (LOOCV) technique. After finding out the optimum wavenumber regions providing high $\mathrm{R}^{2}$, one sample was carefully removed out from the total set data and the calibration model was built using remaining data. The method was repeated for all data to achieve minimum prediction residual error sum of square (PRESS) with highest $\mathrm{R}^{2}$ with certain number of factor used. In this study, we assigned 1-10 factors to build PLS regression model. Both PLS regression model for STE and RBA determination was established using 10 factors to obtain minimum PRESS, highest $\mathrm{R}^{2}$ and minimum root mean square error of cross validation (RMSECV). Furthermore, the candidate model was optimized by calculating PLS regression model with several treatments of spectra. Table 3 presented optimization of PLS regression model with several spectra treatments during STE and RBA determination. FTIR spectral treatment at selected wavenumber region could not improve capabilityof PLS regression established neither for STE nor RBA determination. Furthermore, synergy interval partial least square (siPLS) could increase linearity PLS regression model established. siPLS was optimized by screening selected remaining wavenumber region to achieve better $\mathrm{R}^{2}$ and RMSEC values. 
Table 3: Spectra treatments and PLS regression model for stevioside determination at wavenumbers of $671-1450 \mathrm{~cm}^{-1}(n=3)$

\begin{tabular}{|c|c|c|c|}
\hline Analytes & Spectral treatment & $\mathbf{R}^{2}$ & RMSEC \\
\hline \multirow{9}{*}{ Stevioside } & Original-MSC & 0.9836 & 1.08 \\
\hline & siPLS (671-1450; 3278-3310 $\left.\mathrm{cm}^{-1}\right)$ & 0.9952 & 0.84 \\
\hline & Second derivative & 0.1720 & 2.65 \\
\hline & Baseline correction & 0.9712 & 1.22 \\
\hline & First derivative & 0.5888 & 2.27 \\
\hline & MSC & 0.7520 & 2.00 \\
\hline & Normalization & 0.7479 & 2.02 \\
\hline & Offset correction & 0.8947 & 1.63 \\
\hline & SNV & 0.8909 & 1.64 \\
\hline \multirow[t]{10}{*}{ Rebaudioside A } & Original & 0.9911 & 0.70 \\
\hline & siPLS (921-1508; 2863-2893 $\left.\mathrm{cm}^{-1}\right)$ & 0.9898 & 0.72 \\
\hline & Normalization & 0.8583 & 1.44 \\
\hline & Baseline correction & 0.9911 & 0.70 \\
\hline & First derivative & 0.7096 & 1.72 \\
\hline & Second derivative & 0.6956 & 1.76 \\
\hline & MSC & 0.9562 & 1.06 \\
\hline & Offset correction & 0.8650 & 1.48 \\
\hline & SNV & 0.9526 & 1.09 \\
\hline & Original & 0.9911 & 0.70 \\
\hline
\end{tabular}

SNV = Standard Normal Variate; MSC = Multiplicative Scatter (or Signal) Correction

The correlation between actual value of STE and RBA determined from HPLC analysis and predicted value determined from FTIR spectroscopy combined with PLS regression indicated $\mathrm{R}^{2}>0.99$. The correlation between actual value and predicted value for both STE and RBA were presented in fig. 3 . Finally, the validation capability of optimum PLS model was expressed by RMSEP and coefficient determination $\left(\mathrm{R}^{2}\right)$. These parameters were calculated from correlation between actual value based on HPLC determination and predicted value based on FTIR spectra combined with PLS determination.

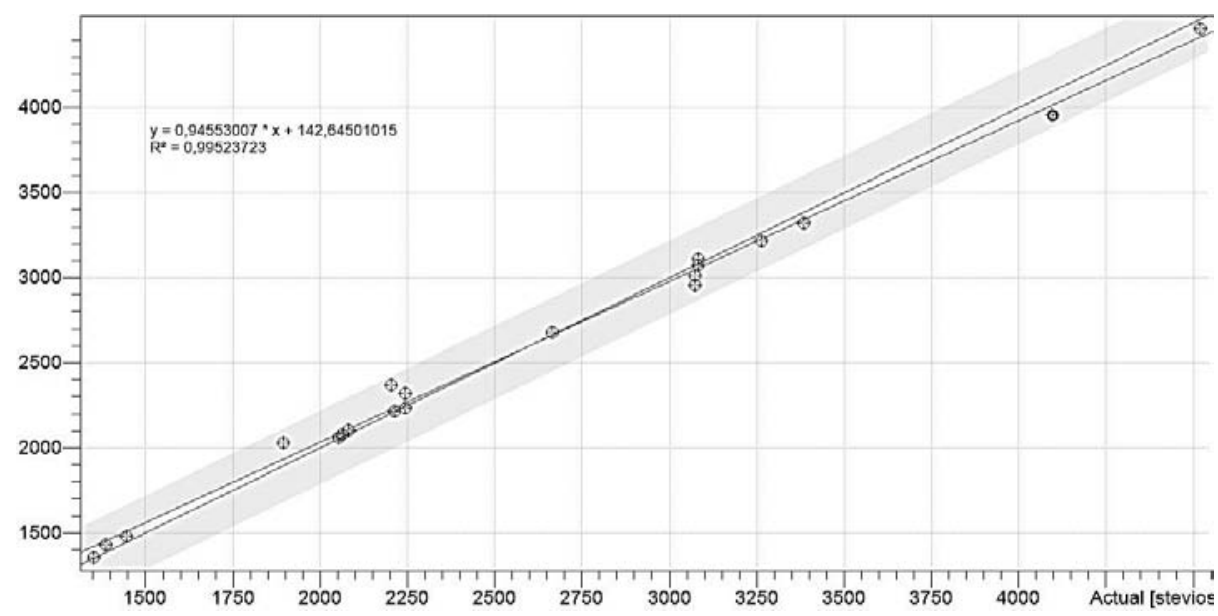

(a)

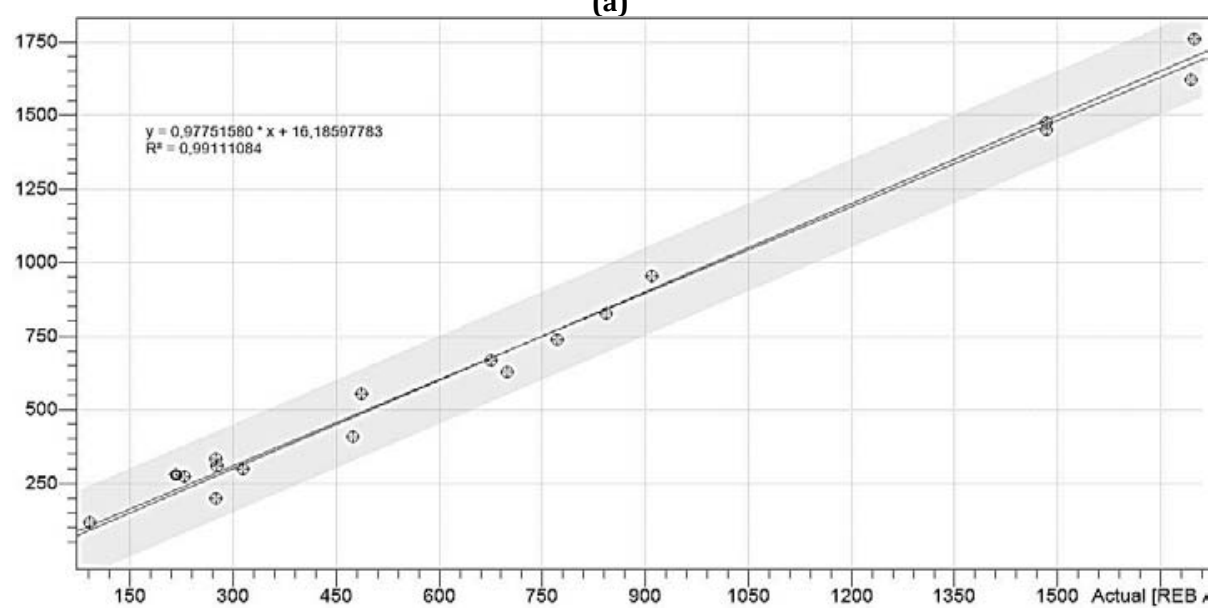

(b)

Fig. 3: Correlation between actual values of (a) stevioside and (b) rebaudioside A in ethanolic extract of Stevia rebaudiana leaves determined by HPLC method ( $\mathrm{x}$-axis) and predicted values using FTIR spectroscopy combined with PLS (y-axis) at wavenumber 671$1450 \mathrm{~cm}^{-1}$ for stevioside (a) and $930-1520 \mathrm{~cm}^{-1}$ for rebaudioside $A$ 


\section{CONCLUSION}

We concluded that FTIR spectroscopy in combination with multivariate analysis of PLS regression could be used an alternative method for determining stevioside and rebaudioside A in Stevia rebaudiana leaves. The method developed was reliable, rapid, practice, and efficient to determine stevioside and rebaudioside A in Stevia rebaudiana leaves extract.

\section{ACKNOWLEDGEMENT}

We thank Java Sakti Niaga Company (Indonesia) which have provided Stevia rebaudiana leaves samples during this research.

\section{AUTHORS CONTRIBUTION}

YM and AR performed research activities and prepared manuscript, designed research, analyzed data, and made critical thinking on manuscript.

\section{CONFLICTS OF INTERESTS}

All authors have none to declare

\section{REFERENCES}

1. Bergs D, Burghoff B, Joehnck M, Martin G, Schembecker G. Fast and isocratic HPLC-method for steviol glycosides analysis from Stevia rebaudiana leaves. J Fur Verbraucherschutz Lebens 2012;7:147-54

2. Lemus Mondaca R, Vega Galvez A, Zura Bravo L, Ah-Hen K. Stevia rebaudiana Bertoni, source of a high-potency natural sweetener: a comprehensive review on the biochemical, nutritional and functional aspects. Food Chem 2012;132:1121-32.

3. Gregersen S, Jeppesen PB, Holst JJ, Hermansen K. Antihyperglycemic effects of stevioside in type 2 diabetic subjects. Metabolism 2004;53:73-6.

4. Shivanna N, Naika M, Khanum F, Kaul VK. Antioxidant, antidiabetic and renal protective properties of Stevia rebaudiana. J Diabetes Complications 2013;27:103-13.

5. Gaweł Bęben K, Bujak T, Nizioł Łukaszewska Z, Antosiewicz B, Jakubczyk A, Karaś M, et al. Stevia rebaudiana bert. leaf extracts as a multifunctional source of natural antioxidants. Molecules 2015;20:5468-86.

6. Kim IS, Yang M, Lee OH, Kang SN. The antioxidant activity and the bioactive compound content of Stevia rebaudiana water extracts. LWT-Food Sci Technol 2011;44:1328-32.

7. Ferri LAF, Alves-Do-Prado W, Yamada SS, Gazola S, Batista MR, Bazotte RB. Investigation of the antihypertensive effect of oral crude stevioside in patients with mild essential hypertension. Phytother Res 2006;20:732-6.

8. Wang LS, Shi Z, Shi BM, Shan AS. Effects of dietary stevioside/rebaudioside $\mathrm{A}$ on the growth performance and diarrhea incidence of weaned piglets. Animal Feed Sci Technol 2014;87:104-9.

9. Takasaki M, Konoshima T, Kozuka M, Tokuda H, Takayasu J. Cancer preventive agents. Part 8: chemopreventive effects of stevioside and related compounds. Bioorganic Med Chem 2009;17:600-5.

10. Liu J, Li J, Tang J. Ultrasonically assisted extraction of total carbohydrates from stevia rebaudiana bertoni and identification of extracts. Food Bio Processing 2010;88:215-21.

11. Well C, Frank O, Hofmann T. Quantitation of sweet steviol glycosides by means of a HILIC-MS/MS-SIDA approach. J Food Agric Chem 2013;61:11312-20.

12. Gardana C, Scaglianti M, Simonetti P. Evaluation of steviol and its glycosides in Stevia rebaudiana leaves and commercial sweetener by ultra-high-performance liquid chromatographymass spectrometry. J Chromatogr A 2010;1217:1463-70.

13. Cacciola F, Delmonte P, Jaworska K, Dugo P, Mondello L, Rader JI. Employing Ultra high pressure liquid chromatography as the second dimension in a comprehensive two-dimensional system for analysis of Stevia rebaudiana extracts. J Chromatogr A 2011;1218:2012-8.

14. Jaworska K, Krynitsky AJ, Rader JI. Simultaneous analysis of steviol and steviol glycosides by liquid chromatography with ultraviolet detection on a mixed-mode column: application to stevia plant material and stevia-containing dietary supplements. J AOAC Int 2012;95:1588-96.

15. Lorenzo C, Serrano Diaz J, Plaza M, Quintanilla C, Alonso GL. Fast methodology of analysing major steviol glycosides from stevia rebaudiana leaves. Food Chem 2014;157:518-23.

16. Chester K, Tamboli ET, Singh M, Ahmad S. Simultaneous quantification of stevioside and rebaudioside $\mathrm{A}$ in different stevia samples collected from the Indian subcontinent. J Pharm Bioalleid Sci 2012;4:276-81.

17. Jaitak V, Gupta AP, Kaul VK, Ahuja PS. Validated highperformance thin-layer chromatography method for steviol glycosides in Stevia rebaudiana. J Pharm Biomed Anal 2008;47:790-4.

18. Hearn LK, Subedi PP. Determining levels of steviol glycosides in the leaves of stevia rebaudiana by near infrared reflectance spectroscopy. J Food Compos Anal 2009;22:165-8.

19. Li H, He J, Li F, Zhang Z, Li R. Application of NIR and MIR spectroscopy for rapid determination of antioxidant activity of radix scutellariae from different geographical regions. Phytochem Anal 2016;27:73-80.

20. Rohman A, Sudjadi, Ramadhani D, Nugroho A. Analysis of curcumin in curcuma longa and curcuma xanthorriza using FTIR spectroscopy and chemometrics. Res J Med Plants 2015;9:179-86.

21. Rohman A, Setyaningrum DL, Riyanto S. FTIR spectroscopy combined with Partial Least Square for analysis of red fruit oil in ternary mixture system. Int J Spectros 2014;2014:e785914. Doi:10.1155/2014/785914.

22. Kamble VV, Gaikwad NB. Fourier transform infrared spectroscopy spectroscopic studies in embelia ribes Burm. F.: a vulnerable medicinal plant. Asian J Pharm Clin Res 2016;9:41-7.

23. Nugrahani I, Dillen N. Rapid assay development of diclofenac sodium coated tablet assay using FTIR compared to HPLC method. Int J Appl Pharm 2018;10:43-50

24. Nugrahani I, Khalida FN. Green method for acetaminophen and ibuprofen simultaneous assay in the combination tablet using FTIR. Int J Appl Pharm 2018;10:77-83.

25. Martono Y, Riyanto S, Rohman A, Martono S. Effect of mobile phase composition, organic modifier, and flow rate on selectivity and retention of stevioside and rebaudioside a on isocratic RP-HPLC analysis. Int J Pharm Clin Res 2015;8:397402

26. Pol J, Hohnova B, Hyotylainen T. Characterisation of stevia rebaudiana by comprehensive two-dimensional liquid chromatography time-of-flight mass spectrometry. J Chromatogr A 2007;1150:85-92.

27. Ceunen S, Geuns JMC. Spatio-temporal variation of the diterpene steviol in Stevia rebaudiana grown under different photoperiods. Phytochem 2013;89:32-8.

28. Chranioti C, Chanioti S, Tzia C. Comparison of spray, freeze and oven drying as a means of reducing bitter aftertaste of steviol glycosides (derived from Stevia rebaudiana Bertoni plant)evaluation of the final products. Food Chem 2016;190:1151-8. 